\title{
Un guide de présentation pour les communications rapides
}

\author{
Correspondance : ccdr-rmtc@phac-aspc.gc.ca
}

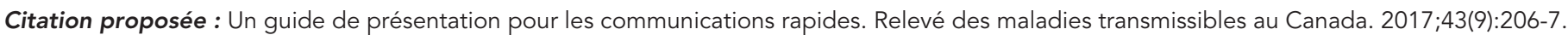
https://doi.org/10.14745/ccdr.v43i09a03f

Une communication rapide est une notification en temps opportun d'un changement dans la nature ou la propagation d'une maladie contagieuse. Elle sert à prévenir qu'un nouvel événement est en cours et pourrait avoir des répercussions immédiates. Par exemple, en décembre 2013, la première transmission locale du chikungunya, un virus transmis par les moustiques, a été confirmée dans plusieurs îles des Caraïbes. Un mois plus tard, les cliniciens au Canada ont été avisés que des patients pourraient présenter une fièvre et une arthralgie après avoir voyagé dans l'une des îles touchées (1). Un an plus tard, le virus chikungunya s'est propagé partout dans les Caraïbes ainsi que dans le monde entier. Au Canada, on a signalé une hausse du nombre de cas d'infections par ce virus liés aux voyages (2). Peu de temps après, une tendance semblable d'expansion s'est manifestée avec le virus Zika (3).

Une communication rapide peut être un rapport préliminaire sur une éclosion ou une alerte relativement à un changement dans la gravité de la maladie, les facteurs de risque, les tendances en matière de transmission, le réservoir, la propagation géographique ou la sensibilité aux traitements offerts. II s'agit d'un résumé des éléments actuellement connus, de l'épidémiologie (personnes touchées), de la méthode de détection, des enquêtes nécessaires pour établir le diagnostic, ainsi que des mesures cliniques et de santé publique à prendre pour y remédier. La différence entre une communication rapide et un rapport d'éclosion est que ce dernier est généralement rédigé une fois l'éclosion terminée. Les communications rapides sont rédigées peu de temps après le début de l'éclosion ou dès qu'un changement s'opère dans l'activité de la maladie. Les rapports de cette nature peuvent parfois être publiés sous forme d'un court exposé si les répercussions ne sont pas considérées comme étant urgentes.

Bien qu'une communication rapide comporte sa part d'avantages en raison de son caractère consultatif qui vise à alerter les gens d'un nouvel événement, elle peut aussi présenter certaines lacunes en raison du manque d'information disponible. Si un nouvel agent pathogène est détecté, il est possible qu'on ne dispose pas de renseignements sur la période d'incubation, le niveau d'infectiosité ou même le mode de transmission. Les premiers cas ne sont pas toujours représentatifs des cas postérieurs à la propagation de la maladie. Par conséquent, dans la section "Évaluation » d'une communication rapide, il faut bien résumer ce qui est connu et ce qui ne l'est pas encore.

Le Relevé des maladies transmissibles au Canada (RMTC) a dressé une liste de vérification comportant 16 éléments pour la production de rapports sur les communications rapides, basée sur les pratiques exemplaires dans les communications scientifiques (tableau 1). Ces rapports comptent généralement entre 1000 et 1500 mots. Comme pour toutes les soumissions, consultez le document Renseignements à l'intention des auteurs du RMTC pour connaître les exigences générales relatives à la préparation et à la soumission des manuscrits (4).
Tableau 1 : Liste de vérification pour la déclaration des communications rapides

\begin{tabular}{|c|c|c|}
\hline $\begin{array}{l}\text { Élément de la } \\
\text { déclaration }\end{array}$ & $\mathrm{N}^{\circ} \mathrm{d}^{\prime}$ élément & Description \\
\hline \multicolumn{3}{|l|}{ Titre ou résumé } \\
\hline Titre & 1 & $\begin{array}{l}\text { Donner un titre qui comprend la } \\
\text { maladie, la population, le lieu et } \\
\text { le moment. }\end{array}$ \\
\hline Résumé & 2 & $\begin{array}{l}\text { Rédiger un résumé non } \\
\text { structuré de } 150 \text { mots. }\end{array}$ \\
\hline \multicolumn{3}{|l|}{ Introduction } \\
\hline $\begin{array}{l}\text { Présentation de } \\
\text { l'enjeu }\end{array}$ & 3 & $\begin{array}{l}\text { Définir le problème et son } \\
\text { déroulement (contexte, } \\
\text { événements). Pourquoi est- } \\
\text { ce important de le déclarer } \\
\text { maintenant? }\end{array}$ \\
\hline \multicolumn{3}{|l|}{ Situation actuelle } \\
\hline Aperçu & 4 & $\begin{array}{l}\text { Déterminer ce qui est connu } \\
\text { à ce jour : le milieu, la date, } \\
\text { le contexte d'apparition de la } \\
\text { maladie et le moment où elle a } \\
\text { été détectée. }\end{array}$ \\
\hline $\begin{array}{l}\text { Description des } \\
\text { cas }\end{array}$ & 5 & $\begin{array}{l}\text { Décrire les personnes touchées, } \\
\text { y compris les symptômes, les } \\
\text { données démographiques } \\
\text { (p. ex. âge, sexe et lieu } \\
\text { d'origine) et la présence } \\
\text { de liens épidémiologiques } \\
\text { entre les cas, d'une façon } \\
\text { qui préserve l'anonymat des } \\
\text { patients. }\end{array}$ \\
\hline $\begin{array}{l}\text { Courbe } \\
\text { épidémiologique }\end{array}$ & 6 & $\begin{array}{l}\text { Fournir une courbe } \\
\text { épidémiologique (s'il y a lieu). }\end{array}$ \\
\hline $\begin{array}{l}\text { Étendue de la } \\
\text { maladie }\end{array}$ & 7 & $\begin{array}{l}\text { Décrire l'ampleur et la gravité } \\
\text { de la maladie, ainsi que les } \\
\text { résultats à ce jour (p. ex. } \\
\text { nombre d'hospitalisations et de } \\
\text { décès). }\end{array}$ \\
\hline Enquêtes & 8 & $\begin{array}{l}\text { Déterminer la façon dont } \\
\text { l'éclosion a été étudiée, y } \\
\text { compris les tests de laboratoire } \\
\text { qui ont été réalisés afin de } \\
\text { déterminer l'agent causal et } \\
\text { le(s) site(s) d'échantillonnage. }\end{array}$ \\
\hline $\begin{array}{l}\text { Agent } \\
\text { responsable }\end{array}$ & 9 & $\begin{array}{l}\text { Décrire et résumer les faits } \\
\text { connus à ce jour à propos de } \\
\text { cet agent. }\end{array}$ \\
\hline Interventions & 10 & $\begin{array}{l}\text { Décrire les mesures cliniques } \\
\text { qui ont été mises en place pour } \\
\text { traiter et gérer les patients } \\
\text { touchés (p. ex. procédures de } \\
\text { prévention et de contrôle des } \\
\text { infections, traitements). }\end{array}$ \\
\hline
\end{tabular}


Tableau 1 : Liste de vérification pour la déclaration des communications rapides (suite)

\begin{tabular}{|c|c|c|}
\hline $\begin{array}{c}\text { Élément de la } \\
\text { déclaration }\end{array}$ & $N^{\circ} d^{\prime}$ élément & Description \\
\hline \multicolumn{3}{|l|}{ Situation actuelle } \\
\hline $\begin{array}{l}\text { Interventions } \\
\text { (suite) }\end{array}$ & 11 & $\begin{array}{l}\text { Décrire les mesures de santé } \\
\text { publique qui ont été mises en } \\
\text { place pour contrôler l'éclosion } \\
\text { (p. ex. définition des cas, } \\
\text { recherche de contacts, gestion } \\
\text { des risques, communications, } \\
\text { etc.). }\end{array}$ \\
\hline \multicolumn{3}{|l|}{ Conclusion } \\
\hline \multirow[t]{2}{*}{ Évaluation } & 12 & $\begin{array}{l}\text { Résumer les renseignements } \\
\text { connus et déterminer ce } \\
\text { qui n'est pas encore connu } \\
\text { (p. ex. mode de transmission, } \\
\text { réservoir pathogène, période } \\
\text { d'incubation estimée, facteurs } \\
\text { de risque et efficacité du } \\
\text { traitement). }\end{array}$ \\
\hline & 13 & $\begin{array}{l}\text { Prendre en compte les } \\
\text { références pertinentes à des } \\
\text { événements semblables ou } \\
\text { antérieurs. }\end{array}$ \\
\hline \multirow[t]{2}{*}{ Répercussions } & 14 & $\begin{array}{l}\text { Tenir compte des répercussions } \\
\text { de l'éclosion sur la pratique } \\
\text { clinique, y compris les } \\
\text { recommandations relatives } \\
\text { à la détermination et à la } \\
\text { gestion des cas, le contrôle } \\
\text { des infections et la production } \\
\text { de rapports. Déterminer les } \\
\text { répercussions sur le sexe et le } \\
\text { genre. }\end{array}$ \\
\hline & 15 & $\begin{array}{l}\text { Tenir compte des répercussions } \\
\text { sur les pratiques en matière } \\
\text { de santé publique, y compris } \\
\text { les recommandations pour } \\
\text { la surveillance, la prévention, } \\
\text { la gestion des risques et les } \\
\text { communications. }\end{array}$ \\
\hline Conclusion & 16 & $\begin{array}{l}\text { Fournir une synthèse des faits } \\
\text { connus à ce jour et indiquer } \\
\text { les efforts futurs qui seront } \\
\text { déployés afin de comprendre et } \\
\text { de contrôler la maladie. }\end{array}$ \\
\hline
\end{tabular}

Abréviation : $\mathrm{N}^{\circ}$, nombre

\section{Références}

1. Deilgat M, Geduld J, Drebot M. Éclosion de chikungunya dans les caraïbes (2013-2014). Relevé des maladies transmissibles au Canada. 2014;40(2):7-12. https://www. canada.ca/fr/sante-publique/services/rapports-publications/ releve-maladies-transmissibles-canada-rmtc/numeromensuel/2014-40/rmtc-volume-40-2-24-janvier-2014/rmtcvolume-40-2-24-janvier-2014.html

2. Drebot MA, Holloway K, Zheng H, Ogden NH. Cas de chikungunya liés au Canada, 2014. Relevé des maladies transmissibles au Canada. 2015;41(1):7-15. https://www. canada.ca/fr/sante-publique/services/rapports-publications/ releve-maladies-transmissibles-canada-rmtc/numeromensuel/2015-41/rmtc-volume-41-01-8-janvier-2015/rmtcvolume-41-01-8-janvier-2015-3.html

3. Kass DE, Merlino M. Zika Virus. N Engl J Med. 2016 Jul 21;375(3):294. PubMed (https://www.ncbi.nlm.nih.gov/ pubmed/27355411?dopt=Abstract).

4. Renseignements à l'intention des auteurs: janvier 2017. Relevé des maladies transmissibles au Canada. https://www. canada.ca/fr/sante-publique/services/rapports-publications/ releve-maladies-transmissibles-canada-rmtc/soumettrearticle-renseignements-a-intention-auteurs.html 